\section{NEURAXIAL CARDIOVASCULAR ACCIDENTAL DRUG ADMINISTRATION ERRORS REVIEW}

'S Patel ${ }^{*},{ }^{2}$ F Dexter. 'Tawam Hospital, Al Ain, United Arab Emirates; ${ }^{2}$ Craver College of Medicine, Iowa, USA

\subsection{6/rapm-2021-ESRA.41}

Background and Aims Neuraxial drug administration errors are catastrophic. ${ }^{1,2,3}$ Inadvertent neuraxial administration of cardiovascular (CV) drugs has not been reviewed previously.

Methods Medline and Google Scholar were searched through December 2020 using terms such as 'epidural drug error', with 'spinal', 'intrathecal', or 'neuraxial'. Error reports analysed were limited to those of CV drugs administered via epidural (ED) or intrathecal (IT) route.

Results 28 case reports/case series describing administration of 10 drugs in 34 patients were identified. Digoxin (9), ephedrine (6), and metaraminol (5) were involved in 20 of the 34 patients (table 1).

Except dopamine (1 patient of 3), phenylephrine, and mexiletine (the patient received infusion after bolus) all administrations were in the form of bolus (table 1).

Abstract 41 Table 1 Drug, route, dose administered and clinical features and management

\begin{tabular}{|c|c|c|c|c|}
\hline Drag & N. NR & $\begin{array}{l}\text { Dese } \\
\text { Adtminiatered }\end{array}$ & Clinical sensegareces and mansevment & Cement \\
\hline Degean & ifit & $\begin{array}{l}0.25 .05 \mathrm{mg} \\
0.25 \mathrm{mg}\end{array}$ & 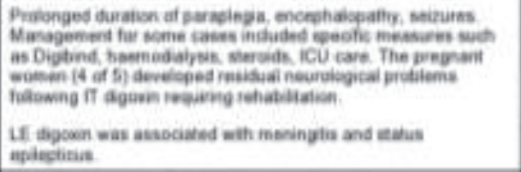 & 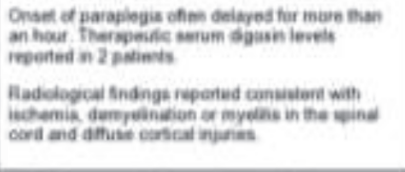 \\
\hline Docutamine & 谟 & $\begin{array}{l}25 \mathrm{ma} \\
10 \mathrm{ing}\end{array}$ & 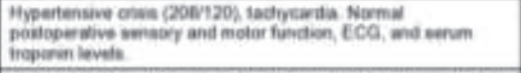 & The TE was used aher realeution of the evor. \\
\hline Dowarne & $\begin{array}{l}\text { 1F: } \\
2 \pi\end{array}$ & 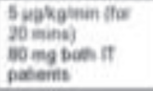 & 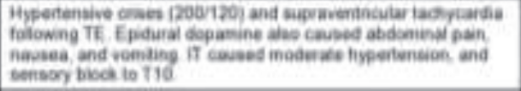 & 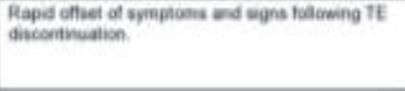 \\
\hline fphedies & OLE & 15.50 ag & 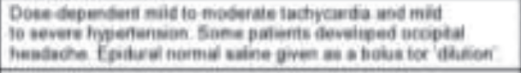 & 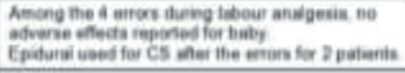 \\
\hline Fpinephine & icE & $\begin{array}{l}300 \mathrm{w0} \\
10 \mathrm{wS}\end{array}$ & 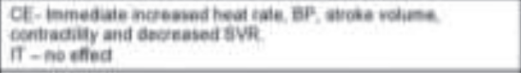 & CF.-indent \\
\hline Labelad & $\begin{array}{l}\text { 3ite } \\
\text { 3it }\end{array}$ & $\begin{array}{l}15 \mathrm{mg} \\
15-26 \mathrm{ng}\end{array}$ & 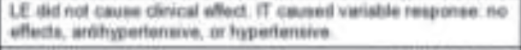 & 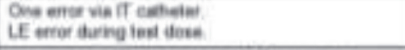 \\
\hline Metarmenel & IIE & Theg & 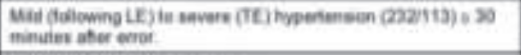 & 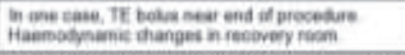 \\
\hline Mesiokne & $1 \mathrm{TE}$ & $\begin{array}{l}\text { Uninaen. } \\
\text { intusion aver } \\
\text { severes hose }\end{array}$ & Hypatensien for beves haus & 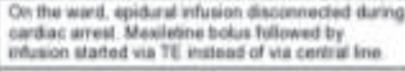 \\
\hline Norepantinn & $1 \pi$ & 40 & 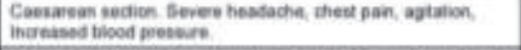 & incorred via douen ue GA teatied. \\
\hline Phenylegherise & $1 \pi$ & $\begin{array}{l}16.2 \mathrm{mg} \text { (inhwen } \\
\text { iver } 12 \text { heors) }\end{array}$ & 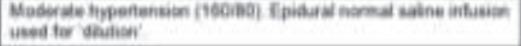 & 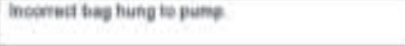 \\
\hline
\end{tabular}

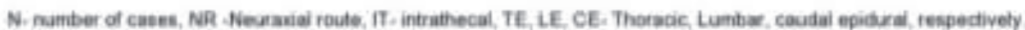

Abstract 41 Table 2 Human factors (https://www.hfacs.com/hfacs-framework.html) contributing to the neuraxial cardiovascular drug

\begin{tabular}{|l|l|}
\hline $\begin{array}{l}\text { Organisational } \\
\text { influences }\end{array}$ & $\begin{array}{l}\text { Purchase of look-alike ampoules, syringes, and vials. } \\
\text { Cardiovascular and local anaesthetic syringes in one anaesthesia tray. } \\
\text { Cardiovascular medications and local anaesthetics stored together. } \\
\text { Failure to make change after previous errors resulting in same hospital having >1 error and of same cause. } \\
\text { Staff scheduling with resident on every other night } 24 \text { hour calls for several consecutive cycles; midwife looking after three } \\
\text { patients during night; and anesthesiologist having worked 19 hours at time of error. }\end{array}$ \\
\hline $\begin{array}{l}\text { Supervisory } \\
\text { factors }\end{array}$ & $\begin{array}{l}\text { One resident involved in two errors. } \\
\text { Nurse breaking and holding wrong ampoule for anaesthetist to withdraw, junior resident broke the ampoule and held for } \\
\text { anaesthetist to withdraw, junior anaesthesia resident broke ampoule and left on anaesthesia workstation and then scrubbed } \\
\text { for procedure and asked other personnel to assist. } \\
\text { First year resident using spinal catheter. } \\
\text { Untrained staff bypassed hospital policy for second nurse to confirm correct medication for ED infusion. } \\
\text { Infusion of wrong high-risk cardiovascular drug via epidural catheter for many hours. }\end{array}$ \\
\hline $\begin{array}{l}\text { Preconditions } \\
\text { for unsafe acts }\end{array}$ & $\begin{array}{l}\text { High-risk medication vial which was bought for another patient left over on anaesthesia trolley. } \\
\text { Fixing the epidural and IV lines nearby over the chest. }\end{array}$ \\
\hline Unsafe acts & Skill based errors (all), incorrect visual perception, exceptional policy violation. \\
\hline
\end{tabular}


IT Digoxin caused long lasting paraplegia in 5 patients. IT or ED vasopressors or inotropes caused reversible haemodynamic changes of variable duration.

Primary causes included ampoule errors (mostly for digoxin and labetalol), syringe swaps (in cases of ephedrine, epinephrine and metaraminol) and ED-IV line confusion (for phenylephrine and mexiletine infusions). NRFit could have prevented 14 (of 34) errors.

Table 2 lists the human factor contributing to the errors. Conclusions Bar coding of both ampoules and syringes would have prevented several errors. In the absence of barcode reader or human double checking, NRFit devices could have prevented 14 misconnection (syringe or IV infusion lines) mistakes. Correction of deficiencies (e.g., high risk CV drug ampoules and syringes location, substandard supervision of anaesthesia residents/assistants) identified using HFACS are also fundamental. Management following neuraxial CV drugs is supportive.

\section{PREPARING INTRATHECAL OPIOID INJECTATE, A 'TIP' FOR SUCCESS}

J Worthington*, A Allan, K Khanna. Great Western Hospital, Swindon, UK

\subsection{6/rapm-2021-ESRA.42}

Background and Aims The technique of drawing up opioids for spinal anaesthesia can lead to error. We identified stages in the process which could be overlooked by the anaesthetist causing inadvertent overdosing or underdosing of opioids. This error is usually made by inclusion of residual fluid in the tip of the syringe, due to withdrawing the opioid in the $1 \mathrm{ml}$ syringe (figure $1 \mathrm{a}$ ) rather than injecting (figure $1 \mathrm{~b}$ ). The tip contains $0.05-0.07 \mathrm{mls}$, of greatest significance when dealing with small and concentrated amounts of opioid. We aimed to survey the department to identify the proportion of anaesthetists that were using a technique leading to inadvertent error.

Methods We identified fifty-seven anaesthetists in the department and surveyed their process of drawing up drugs for intrathecal injection. The main focus of the survey was the technique used to transfer the opioid into the spinal syringe injectate including the use of the filter needle.

Results Data was captured from 47/57 anaesthetists, the majority consultants. $40 \%$ of the department were administering a dose error of spinal fentanyl. 35\% of the department were administering a dose error of spinal morphine and diamorphine. The filter needle was used inappropriately in $14 \%$ of cases.

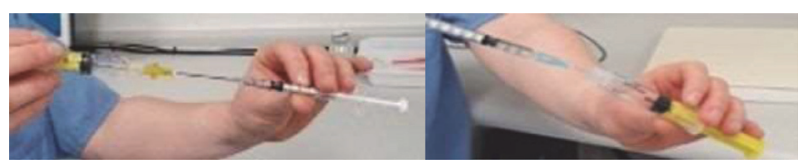

\section{Abstract 42 Figure 1}

Conclusions Precision is essential in regional anaesthesia when using small and concentrated amounts of opioid in the injectate, therefore the inclusion of the amount in the tip can lead to significant dose error. We presented the results and re-educated the department in our clinical governance meeting.

\section{GENERAL OR REGIONAL ANAESTHESIA FOR MICROVASCULAR FLAP SURGERY: COMPARISON OF SURGICAL COMPLICATION RATE AND DURATION OF HOSPITALIZATION}

RP Ročāns*, B Mamaja, S Doniṇa. Riga Stradins University, Riga, Latvia

\subsection{6/rapm-2021-ESRA.43}

Background and Aims Microvascular flap surgery is an effective method for difficult reconstructions and major defects.[1] There is an ongoing debate about the preferred method of anaesthesia for flap success.[2] We aim to evaluate the differences in the rate of microvascular flap surgery complications and duration of hospitalization between patients receiving regional anaesthesia (RA) and general anaesthesia (GA).

Methods This retrospective cohort study includes 54 adult patients undergoing elective microvascular flap surgery. The study was approved by the Ethics Committee of Riga Stradins University. The method of anaesthesia was chosen according to individual surgical necessity. Patients were divided into two groups - RA group $(\mathrm{N}=25)$ and GA group $(\mathrm{N}=29)$. Postoperative outcome data on surgical flap complications, duration of intensive care stay, and total duration of hospitalization was obtained.

Results RA and GA groups had no statistically significant differences in the rate of flap failure, infection, hematoma, or any other type of flap complication. GA group had a mean intensive care stay duration of 2.33 days (CI95\% $0.62-5.25$ ). RA group had a significantly lower mean intensive care stay duration of 0.26 days $(0.06-0.57 ; \mathrm{p}=0.002)$. GA group had a mean hospitalization duration of 24.4 days (14.42-34.31). RA group had a comparatively lower mean hospitalization duration of 14.25 days $(9.55-19.01 ; \mathrm{p}=0.032)$.

Conclusions The rate of surgical complications in microvascular flap surgery is equal for both RA and GA. Patients who receive GA have a longer mean intensive care stay and duration of hospitalization. In contrast to previous assertions, a meticulously administered regional anaesthesia might be preferred when surgically feasible.

\section{RETROLAMINAR PARAVERTEBRAL CATHETERS FOR RIB PLATING SURGERY - A CASE SERIES}

EEL Ng*, SX Ho, CHJ Ong, J Tan, LL Lean, W-S Choo. Ng Teng Fong General Hospital, Singapore, Singapore

\subsection{6/rapm-2021-ESRA.44}

Background and Aims The ultrasound-guided retrolaminar technique to paravertebral blockade (RLB) is safe, easy and minimally invasive for use in mastectomies1, analgesia for rib fractures2, and analgesia post thoracic surgery3 with reduced risks of pneumothorax and structural injury and reduced spread of injectate. Though literature described higher volume boluses followed by infusions, we present our experience with in-plane ultrasound-guided RLB catheter using moderate volume boluses twice daily (BD) for rib fixations.

Methods Five cases of ultrasound-guided retrolaminar paravertebral block catheter were observed between May 2019 and March 2020 in our institution who sustained multiple rib fractures and underwent surgical fixation. Details of the patients are presented in tables 1-2.

Results Patients' satisfaction is high - low pain scores shows that the degree of analgesia is more than adequate, with bolus 